\title{
HARRIET ANN JACOBS: FEMINISMO E LITERATURA
}

\section{HARRIET ANN JACOBS: FEMINISM AND LITERATURE}

\author{
Alessandra Ramos de Oliveira Harden ${ }^{1}$ \\ Luciene do Rêgo da Silva ${ }^{2}$
}

RESUMO: Este artigo concentra-se na apresentação de Incidents in the Life of Slave Girl (1861), de Harriet Ann Jacobs, com base na noção de autobiografia proposta por Philippe Lejeune (2008). Propõe-se um entrecruzamento desse gênero com as teorias feministas, com ênfase no feminismo negro, devido à relevância da obra para a Literatura negra e feminista, bem como para o Movimento Feminista e os Movimentos Negros do Brasil. Tendo em vista que se trata de escrita autobiográfica, com o relato de uma mulher em situação de escravidão nos Estados Unidos do século XIX, defende-se que a leitura de Incidents nos ajuda a compreender a importância da voz da mulher negra escravizada no Brasil, diante da escassez de registros acerca de obras literárias escritas por pessoas nessa situação.

PALAVRAS-CHAVE: Harriet Ann Jacobs. Mulher Negra Escravizada. Feminismo Negro. Autobiografia.

\begin{abstract}
This article is an introduction to Incidents in the Life of Slave Girl (1861) by Harriet Ann Jacobs based on on Philippe Lejeune's concept of autobiography (2008). The article proposes an intersection of this genre with feminist theories, especially black feminism, due to the relevance of the work in Black and Feminist Literature, as well as for the Black and Feminist movements in Brazil. Considering that Jacobs' autobiographical work portrays the life of a $19^{\text {th }}$ century
\end{abstract}

\footnotetext{
${ }^{1}$ Doutora em Estudos Hispânicos e Lusófonos (2010) pela University College Dublin, Irlanda. Mestre em Linguística Aplicada (2002) pela Universidade de Brasília. Graduação em Direito (1994) pela Associação de Ensino Unificado do Distrito Federal (AEUDF). Graduação em Letras - Tradução (1993) pela Universidade de Brasília. Professora do Departamento de Línguas Estrangeiras e Tradução da Universidade de Brasília. Brasília, Distrito Federal, Brasil. E-mail: oliveira.ales@gmail.com

2 Mestranda em Estudos da Tradução pela Universidade de Brasília (POSTRAD/UnB). Graduada em Letras Português/Francês (2015) pela Universidade Federal do Piauí. Brasília, Distrito Federal, Brasil. E-mail: rslucy@hotmail.com
} 
slave woman in the United States, we argue that Incidents helps us better understand the importance of the voices of enslaved black women in Brazil, which is particularly necessary due to the scarcity of national literary works by such women.

KEYWORDS: Harriet Ann Jacobs. Enslaved black Woman. Black feminism. Autobiography. 


\section{INTRODUÇÃO}

Durante muito tempo, as vozes das mulheres negras foram silenciadas. Essas mulheres vinham de uma realidade em que seu corpo era duplamente objetificado, e isso se manifestou também na literatura, universo no qual eram representadas como o Outro. Como consequência, os textos que escreveram somente começaram a ser descobertos no século XX e começo do século XXI. Entretanto, essas mulheres já escreviam desde o século XVIII, como é evidenciado pela história de Rosa Maria Egipcíaca da Vera Cruz, autora de Sagrada Teologia do Amor Divino das Almas Peregrinas (VERA CRUZ, 1763); que é considerado um dos mais antigos livros escritos por uma mulher negra na história do Brasil (MOTT, 1993; 2005).

No século XIX, a maranhense Maria Firmina dos Reis publicava o que seria o primeiro romance da literatura brasileira, Úrsula, em 1859 (MENDES, 2011), a que acrescentaria outras obras, como: Gupeva, em 1861 (1975a); Cantos à beira-mar, de 1871 (1975b); A escrava, um conto que data de 1887; e o Hino à liberdade dos escravos, de 1888 (2011).

Vale destacar outro texto, do fim do século XVIII, escrito por Esperança Garcia, uma mulher escravizada que dirigiu ao governador da Província do Piauí uma carta datada de 6 de setembro de 1770 (MOTT, 1985, 2010). Trata-se de 'inusitada reclamação' (MOURA, 2004), como explica Ferreira (2015, p. 1), pois uma escrava 
se dirige à principal autoridade do Piauí colonial setecentista. A 'Carta' é certamente um dos registros escritos mais antigos da escravidão no Brasil, escrito pelo próprio escravo negro, no nosso caso uma mulher negra e cativa, Esperança Garcia, o que confere à narrativa epistolar em estudo o status de uma escritura da gênese literária afro-brasileira. (SOUZA, 2015, p. 1).

Hoje, a carta redigida por Esperança Garcia vem sendo reivindicada como a mais antiga petição escrita por uma mulher no Brasil pela Comissão da Verdade da Escravidão da OAB - PI e tem o intuito de "mostrar que ainda no ordenamento jurídico vigente, a carta escrita por Esperança Garcia era um habeas corpus, um grito de socorro que trouxe esperança para os escravos piauienses", conforme a fala do presidente da OAB, Chico Lucas ${ }^{3}$.

Já no século XX, não se pode esquecer de Maria Carolina de Jesus, cuja obra pode ser exemplificada pelo livro Quarto de Despejo (1960), marcado pelo diálogo constante com a realidade, autores reconhecidos, críticas sociais e políticas, e questionamentos sobre seu lugar de fala e sobre o lugar em que vive com sua família.

Apesar desses nomes, representantes da força da literatura escrita pela mulher negra, existe ainda uma lacuna na história da escravidão, bem como na literatura negra, poucos escritos de pessoas escravizadas ou ex-escravas e principalmente de mulheres negras brasileiras. Nossa história foi contada pelo Outro e não por nós, como exposto acima. Grande parte da história das mulheres negras escravizadas é oriunda dos Estados Unidos através da literatura e do cinema. Também pode se perceber que a maioria das narrativas da escravidão estadunidense que chega ao Brasil tem a autoria de homens negros, como: $A$ Narrativa da Vida de Frederick Douglass, Um Escravo Americano: Escrita Por Ele Mesmo, escrita por Frederick Douglass e publicada no Brasil em 2016; e 12 Anos de Escravidão, escrita por Solomon Northup e publicada no Brasil em 2014.

Nesse sentido, a voz da mulher negra é muito importante para que seja possível se desmistificar o mito da democracia racial, que romantizou o estupro e as opressões das sujeitas negras, conforme se observa no clássico Casa-Grande \&Senzala (FREYRE, 2005), já objeto de discussão alhures (ver, por exemplo, Giacomini, 1988; Nascimento, 2016).

Bakusis e Krueger (VIEIRA, 2015) também apontam para o fato de que, como a maioria das pessoas escravizadas era analfabeta, os textos dessa época são escritos em terceira pessoa, característica bastante diferente do que ocorre no contexto estadunidense. Nesse sentido, acreditamos que essa autobiografia tem relevância para os estudos negro-feministas e para a literatura traduzida.

Assim, o principal questionamento aqui é avaliar até que ponto a literatura negro-feminista de origem estrangeira seria importante para o feminismo negro no Brasil. Seria possível tentar compreender nosso passado, ou re-construir nossa memória, recorrendo a uma autobiografia como a de Harriet, tendo em vista a

3 OAB Piauí. Projeto Esperança Garcia é apresentado pela Comissão da OAB-PI. Disponível em: http://www.oabpi.org.br/acervo/pagina/1926 Acesso: 28 out. 2017. 
grande lacuna, na história e na história da literatura negra do período escravagista brasileiro, a respeito das obras de autoria de mulheres negras?

Para analisarmos esses questionamentos subdividimos este artigo em partes, que são: i) vida e obra de Harriet; ii) a importância de Incidents na literatura negro-feminista dos EUA; iii) feminismos e feminismos negros; iv) literatura autobiográfica e feminismo negro e, por fim, as considerações finais.

\section{HARRIET ANN JACOBS: VIDA E OBRA}

Harriet Ann Jacobs é um nome que faz parte da história das mulheres negras e da escravidão estadunidense. Reconhecida inclusive por sua participação nos movimentos feminista e abolicionista, foi a primeira mulher negra a escrever sua própria história, publicando seu texto originalmente sob o pseudônimo de Linda Brent.

Harriet Ann Jacobs nasceu em condição de escrava em 11 de fevereiro de 1813, mas conseguiu fugir da escravidão em 1830. Foi atuante no movimento abolicionista dos Estados Unidos e tornou-se amiga de outras mulheres envolvidas com a luta pelo fim da escravidão, como Amy Post, mencionada diversas vezes em Incidents por ser uma pessoa próxima, com a qual Jacobs trocou correspondências e por quem foi encorajada a escrever suas memórias.

Jakobs publicou sua autobiografia, Incidents in the Life of a Slave Girl, em 1861, como Linda Brent, talvez por precisar se manter no anonimato. Essa obra é considerada uma das narrativas mais profundas e consistentes escritas no período anterior à guerra civil americana (BOLDEN, 2000). A narrativa, escrita em primeira pessoa, retrata a vida de Harriet desde a infância até a idade adulta. Como se pode imaginar, é uma história de sofrimento: a autora conta da vida como criança na fazenda de seus senhores; do assédio que passa a sofrer, já na adolescência, por parte de seu proprietário; da tentativa — que resultou vã — de escapar do cativeiro por meio da relação com um advogado branco; dos filhos que teve; da fuga e dos sete anos em que viveu escondida na casa de sua avó materna, local em que podia ficar perto dos filhos, observando-os crescerem.

Após fugir para os estados do Norte, ainda sem os filhos, Harriet vive o medo de ser capturada e a necessidade de juntar dinheiro para tentar comprar sua liberdade e a de seus filhos. Tendo conseguido trabalho com uma família inglesa como babá e vivendo agora em Nova York, restabelece contato com sua filha Matilda, que vive como uma criada com uma família do Sul na cidade. Embora não seja denunciada pelas pessoas para quem trabalha, Harriet sofre porque seu proprietário empreende diversas viagens com a intenção de recapturá-la, além de enviar algumas cartas com a assinatura de familiares, exigindo o retorno dela ao seu lar escravo e prometendo que ela não seria maltratada caso atenda o chamado. O filho de Harriet, Benjamin, é enviado a Nova York para ficar em sua companhia. Harriet coloca-o em uma escola, como aprendiz, e Matilda, em uma escola para se alfabetizar, sob a responsabilidade de uma amiga. Assim, Harriet 
embarca para a Inglaterra após o falecimento da esposa de seu patrão com a finalidade de conseguir economizar mais dinheiro para a educação de seus filhos. No entanto, a ascendência negra de Benjamin é descoberta e ele passa a ser hostilizado na escola, motivo pelo qual decide embarcar em um navio baleeiro. Harrietvolta a trabalhar como como babá para a família inglesa. O seu patrão havia, então, se casado com uma aristocrata americana, que se opunha à escravidão e que se tornou grande amiga e defensora de Harriet, ajudando-a fugir mais de uma vez com sua bebê.

Durante a Guerra Civil dos Estados Unidos, Harriet retornou ao Sul e trabalhou, em Alexandria e em Savannah, como assistente e advogada em benefício de pessoas negras que fugiram para as linhas de frente e lutaram pela União. Ela contou sua história para a imprensa do norte e, quando a violência racista tomou conta do Sul, refugiou-se em Massachusetts e depois em Washington, D. C., onde faleceu em 1987.

Incidents in the Life of a Slave Girl, ou Incidentes na Vida de uma Garota Escravizadaé uma narrativa de natureza autobiográfica e feminista. No Brasil, foi traduzida em 1988 por Waltensir Dutra, em edição publicada pela Editora Campus.

\section{A IMPORTÂNCIA DE INCIDENTS NA LITERATURA NEGRO-FEMINISTA DOS EUA}

Em Ohio, o Anti-Slavery Bugle, de Salem publicou um comentário sobre o livro e insistiu com os abolicionistas do Oeste para que o adquirissem, um dólar o exemplar, do AntiSlavery Office de Boston. O comitê Hovey pagou a Harriet cem dólares pelos exemplares, presumidamente para serem distribuídos a agentes abolicionistas, e em meados de fevereiro o National Anti-Slavery Standard estampava uma carta comparando os Incidentes com A Cabana do Pai Tomás, aprovando a sua falta de sensacionalismo e deplorando seu tom por vezes moralizante [...]. O Standard comentou formalmente o livro na semana seguinte, mencionando que podia ser encontrado no Anti-Slavery Office, em Nova Iorque. (YELIN, 1988, p. 12.Grifo nosso).

O livro de Harriet foi amplamente divulgado pelos abolicionistas e suas organizações, obtendo sucesso desde a sua publicação em 1861 nos EUA. É uma narrativa que tem um caráter de reescrita da escravidão, trazendo um viés de um feminismo diverso do proclamado pelas teóricas brancas. EmIncidents, pode-se observar que as mulheres negras que foram escravizadas nos EUA viveram situações similares às irmãs negras brasileiras. 
Quando falamos do mito da fragilidade feminina, que justificou historicamente a proteção paternalista dos homens sobre as mulheres, de que mulheres estamos falando? Nós, mulheres negras, fazemos parte de um contingente de mulheres, provavelmente majoritário, que nunca reconheceram em si mesmas esse mito, porque nunca fomos tratadas como frágeis. Fazemos parte de um contingente de mulheres que trabalharam durante séculos como escravas nas lavouras ou nas ruas, como vendedoras, quituteiras, prostitutas... Mulheres que não entenderam nada quando as feministas disseram que as mulheres deveriam ganhar as ruas e trabalhar! Fazemos parte de um contingente de mulheres com identidade de objeto. Ontem, a serviço de frágeis sinhazinhas e de senhores de engenho tarados. (CARNEIRO, 2003, p. 1).

Na passagem acima, Sueli Carneiro expõe a diferença básica entre a mulher negra e latina, de um lado, e a mulher branca, de outro: a suposta necessidade de proteção frente ao trabalho, que obviamente não se aplicou às mulheres escravizadas, que sempre tiveram que trabalhar. Nesse sentido, os traços de identidade ligados à desvalorização enquanto seres humanos e à visão do trabalho como algo degradante e indigno se repetem na situação das mulheres escravizadas aqui e nos EUA.

As semelhanças infelizmente se fazem presentes também no que diz respeito à violência sexual sofridas, das quais as narratas por Harriet, longe de serem fatos isolados, são apenas exemplos. Interessantess e fazem aqui as palavras de Angela Davis, que, voltadas para as mulheres negras americanas, também descrevem a realidade vivenciada pelas negras escravizadas no Brasil:

Como mulheres, as escravas eram inerentemente vulneráveis a todas as formas de coerção sexual. Enquanto as punições mais violentas impostas aos homens consistiam em açoitamentos e mutilações, as mulheres eram açoitadas, mutiladas e também estupradas. O estupro, na verdade, era uma expressão ostensiva do domínio econômico do proprietário e do controle do feitor sobre as mulheres negras na condição de trabalhadoras.(DAVIS, 2016, p. 20).

Como se pode ver nos excertos de Carneiro e Davis, as mulheres negras estadunidenses e brasileiras estiveram em situação similar de opressão e cativeiro. Desse modo, evidencia-se a importância do recorte de raça dentro das teorias feministas e da literatura feminista, que são empregadas no presente artigo. Com isso, pretende-se chamar a atenção para a necessidade de uma teoria feminista que englobe as questões de gênero e raça e suas especificidades, daí a importância do feminismo negro. 
No movimento feminista, há várias correntes que visam a atender diferentes demandas de mulheres que estão em variados contextos de opressão e violência. De acordo com a classe social, raça ou identificação de gênero, os feminismos foram se subdividindo.

Há muitas desigualdades entre mulheres por desvendar nas práticas domésticas cotidianas, por exemplo, expondo a necessidade repensar referências usuais sobre história das mulheres, dos feminismos e relações de gênero. Representações coletivas sobre ser mulher, tanto presidem o formato das redes de proteção e de dependências e de relações sociais diversas, como fixam limites ao poder social das mulheres, mas no interior de hierarquias que as distinguem umas das outras. Isso se torna mais perceptível naquilo que têm movido, em toda parte, as lutas feministas: as saídas das mulheres para o espaço público. (COSTA, 2004, p. 27).

Dessas correntes verifica-se que há algumas mais relevantes, pois esses movimentos podem ser interpretados em diferentes âmbitos, tais como o político, o econômico, o cultural e o social. Ao se pesquisar os diversos tipos de feminismos, encontram-se controvérsias conforme a classificação. Desse modo, nesse artigo elencamos os que se encontram em mais destaque ${ }^{4}$.

\section{Feminismo individualista}

Este é o feminismo inspirado pelo trabalho e pela luta das primeiras feministas. Advoga igualdade e a retirada das categorias homem e mulher. Opõese ao paternalismo estatal e evoca as reclamações das primeiras feministas, ressaltando que a mulher deve ter direitos e deveres iguais aos homens. Acreditase que o que determina a classe a que uma pessoa pertence é sua relação com o Estado. As intelectuais do século XIX influenciaram bastante esse tipo de feminismo, essas intelectuais comparavam a opressão vivenciada pelas mulheres à opressão dos "escravos".

\footnotetext{
${ }^{4}$ A classificação que se segue não é oriunda de um artigo em específico ou de uma pesquisa acadêmica, mas é fruto de pesquisas em vários sites feministas, que foram considerados devido a sua capacidade de registrar mudanças rápidas de comportamento e de opinião.
} 
O feminismo liberal tem suas raízes na Revolução Francesa e luta pela emancipação da mulher. Define a situação da mulher como resultado de um sistema de desigualdades e não como fruto da opressão e exploração. Opõe-se à censura, como um todo, inclusive à pornografia. Reivindica igualdades entre os sexos e a participação da mulher na esfera política, que podem ser atingidos por meio da equivalência de poder socioeconômico. Esta vertente admite que homens possam ser considerados feministas.

\section{Feminismo radical}

Argumenta que a instituição social que determina os papéis inerentes ao gênero é a razão para as diferenças sociais e que a causa da subordinação está no sistema opressor patriarcal. Teve sua origem na segunda onda de 1960. É contrário à pornografia e à prostituição, vendo essas atividades como fontes de segregação financiadas pelo patriarcado. Dentro desta linha, há algumas subdivisões. Em 2010, com o auge do feminismo na internet, surgiu um grupo denominado "radfem". Essa corrente evoca uma feminilidade baseada no sexo biológico e defende que só podem ser consideradas mulheres quem tem vagina e útero.

\section{Feminismo interseccional}

O feminismo interseccional vê as mulheres como um grupo heterogêneo e com demandas específicas. Esse tipo de femismo procura relacionar as diferenças de classe social, raça, orientação sexual, deficiência física. Surge a partir da crítica das feministas negras e pessoas homofetivas ou contrárias a definição binária dos papéis de gênero e que não se viam inclusas no feminismo de um modo geral. Têm-se como exemplo de feminismos interseccionais: o feminismo negro, feminismo queer, feminismo lésbico e transfeminismo.

\section{Feminismo queer}

O feminismo queer questiona o binarismo do sistema categórico de gêneros (mulheres e homens) e afirma que essa categorização deixa de fora as pessoas que não estão reconhecidas biologicamente como mulheres como: as travestis, lésbicas, drag queens $\mathrm{e}$ todas as outras que fogem da 
heteronormatividade. Essa corrente afirma que a categoria gênero é passível de questionamento e pode ser considerada opressiva quando se refere apenas a diferenças sexuais.

\section{Feminismo negro}

O feminismo negro nasce nos EUA e, desde o século XIX, pode ser identificado a partir das vozes das sujeitas negras escravizadas que se rebalavam contra o sistema de dominação patriarcal e branco. Em 1851, quando Sojourner Truth questionousobre ela ser ou não uma mulher, “Ain't I a Woman”, percebe-se que essa sujeita vivia uma condição subalternizada e reivindicava seu reconhecimento como um ser humano. $\mathrm{O}$ feminismo negro pode ser visto como um tipo de feminismo interseccional por relacionar gênero e raça.

Harriet Jacobs, a autora de Incidents in the Life of a Slave Girl, escreve sobre sua história de opressão e violências vivenciada em uma localidade da região Sul dos Estados Unidos e direciona sua escrita às mulheres do Norte. Incidents é considerada por si só como uma autobiografia que advoga o feminismo negro, mesmo que ainda inconscientemente, já que na época não havia essa nomenclatura, e que retrata a condição da mulher negra escravizada do século XIX. O feminismo negro surgiu no contexto da escravidão e tem várias sujeitas enunciadoras e militantes dessa causa.

Entretanto, na década de 1970,o feminismo negro adquiriu essa denominação quando ativistas norte-americanas viram a interceccionalidade como fator que diferenciava o feminismo defendido por elas do feminismo advogado pelas mulheres brancas de classe média. Essas mulheres formavam um grupo intitulado Combahee River Collective, o qual não levava em conta os diferentes níveis de opressão vivenciados pelas mulheres de cor. Nessa mesma década, os feminismos negro e o interseccional ganharam as ruas e se expandiram para a academia, adquirindo um discurso teórico e crítico. As teóricas Patricia Hill Collins, Angela Davis, Bell Hooks e Keimberlé Crenshaw foram pioneiras na produção de obras que trazem os questionamentos e reflexões base para o feminismo negro estadunidense.

No Brasil, durante a terceira onda do feminismo, nos anos 1980, o feminismo negro surgiu como uma reivindicação das feministas negras que não se sentiam contempladas nas pautas das feministas brancas e que percebiam que o fator da raça influenciava na falta de acesso a políticas de educação, saúde, moradia, e concordavam que suas demandas eram diversas das do movimento de um modo geral. 
O feminismo promoveu uma perspectiva universalista num discurso voltado para uma irmandade entre as mulheres e, desta forma, não dava ênfase às diferenças. É na década de 1980, diz Araújo (2001), que no seio do movimento feminista as mulheres negras começam a levar para as discussões as suas especificidades, tremulando uma nova bandeira de que eram mulheres, mas eram negras, logo, com especificidades da raça. (RAIMUNDO; GEHLEN; ALMEIDA, 2006, p. 4).

Devido ao não acolhimento do movimento feminista (de um modo geral) aos questionamentos levantados pelas mulheres negras, estas acabam por militar em duas vertentes, a racial e a de gênero. Assim, essas mulheres questionam os discursos machistas e as diferenças sociais entre elas e as mulheres brancas. Sueli Carneiro ressalta que as mulheres negras passam por situações muito mais difíceis de acesso aos direitos básicos, desde a escravatura até os dias atuais, tendo muitas vezes apenas mudado suas profissões, porém, ainda ocupando as piores posições de trabalho, muitas vezes informal (CARNEIRO, 2003).

Durante o Brasil império, essas mulheres estavam nas cozinhas, nos serviços domésticos e nas lavouras, e esses postos ainda continuam sendo ocupados por essas mesmas mulheres. Algumas profissões apenas adquiriram outra denominação, mas o lugar da mulher negra ainda continua sendo o da servidão.O feminismo acadêmico ainda tem poucas produções na área do feminismo negro e as publicações aqui no Brasil não atingiram um grande impacto nos estudos feministas como as produções dos Estados Unidos. Sueli Carneiro (2003) chama a atenção para a necessidade de enegrecer o feminismo.

Enegrecer o movimento feminista brasileiro tem significado, concretamente, demarcar e instituir na agenda do movimento de mulheres o peso que a questão racial tem na configuração, por exemplo, das políticas demográficas, na caracterização da questão da violência contra a mulher pela introdução do conceito de violência racial como aspecto determinante das formas de violência sofridas por metade da população feminina do país que não é branca; introduzir a discussão sobre as doenças étnicas/raciais ou as doenças com maior incidência sobre a população negra como questões fundamentais na formulação de políticas públicas na área de saúde; instituir a crítica aos mecanismos de seleção no mercado de trabalho como a 'boa aparência', que mantém as desigualdades e os privilégios entre as mulheres brancas e negras. (CARNEIRO, 2003, p. 3).

Da mesma forma que o feminismo negro tem procurado se inserir na agenda política do movimento feminista, sua existência e consolidação no movimento feminista acadêmico é muito relevante, em todos os âmbitos de estudo e inclusive nos estudos da tradução. Hoje em dia, encontram-se ainda poucas autoras, assim como tradutoras negras e/ou que usem o recorte do feminismo negro em seus trabalhos. Todavia, crê-se que, com o aumento de 
programas de mestrado e doutorado na área de tradução no Brasil, essa realidade tende a se modificar. Este estudo tem como enfoque, portanto, contribuir para essa mudança.

\section{LITERATURA AUTOBIOGRÁFICA E FEMINISMO NEGRO}

O gênero autobiografia pode ser entendido como uma "narrativa retrospectiva em prosa que uma pessoa real faz de sua própria existência, quando focaliza sua história individual, em particular a história de sua personalidade" (LEJEUNE, 2008, p. 14). Para que uma obra seja identificada como autobiografia, há, portanto, diversos elementos que devem ser levados em conta: a forma de linguagem; o assunto tratado; a situação do autor e a posição do narrador. Se alguma dessas características não for específica da autobiografia, a obra em análise deve ser classificada como outro gênero literário: memórias; biografia; romance pessoal; poema autobiográfico; diário; auto-retrato ou ensaio.

Esse tema é relevante porque Incidents in the Life of a Slave Girl ficou por muito tempo conhecida como um romance ("novel"), ou seja, uma obra de ficção. Seu reconhecimento como autobiografia se deu graças ao trabalho incansável de Jean Fagan Yellin, que pesquisou a vida de Jacobs em seu doutorado no sentido de tentou provar que Incidents era uma história verídica após encontrar alguns indícios de sua hipótese. Yellin dedicou mais de 20 anos a essa tarefa, e finalmente conseguiu provar que i) Linda Brent e Harriet Jacobs eram a mesma pessoa; ii) a mulher negra Harriet Jacobs havia de fato existido, e iii) Incidents era uma autobiografia que expunha a escravidão.

Logo no prefácio do livro, escrito por L Maria Child, a organizadora do texto afirma que apenas reviu o original e que fez apenas algumas modificações com o objetivo de condensar o texto ou organizá-lo logicamente. Partindo desse dado, um dos primeiros questionamentos de Yellin sobre Incidents seria de como foi possível para uma mulher, na condição em que vivia Jacobs, escrever sua própria história? Uma mulher negra em condição de escravidão teria tido recursos linguísticos para uma escrita tão rebuscada, como o texto como o texto de Jacobs? Onde essa mulher teria adquirido tal educação e o domínio da norma culta da língua inglesa em pleno século XIX em meio à escravidão? Seria verdade o que Lydia Maria Child declarava sobre a veracidade da autoria?Com base nesses questionamentos, Yellin conseguiu, após intensas pesquisas, provar a veracidade da autoria e o reconhecimento da obra não mais como uma Novel, mas como uma autobiografia (YELLIN, 2004).

Yellin partiu do ponto em que Maria Child declarava, no prefácio da edição, que o texto fonte havia apenas sido revisado, que a forma da escrita, os recursos sintáticos e as figuras de linguagem haviam sido todos selecionados pela autora, e que as modificações foram feitas no original apenas com o intuito de condensar e organizar a narrativa, conforme solicitação da própria Harriet: 
A seu pedido, revisei seu manuscrito, mas as mudanças que fiz foram principalmente com o propósito de condensação e disposição lógica. Não adicionei nada aos incidentes ou alterei o conteúdo de suas observações muito pertinentes. Com insignificantes exceções, as idéias e a linguagem são dela. Podei um pouco os excessos, porém as idéias e a linguagem são dela, mas, fora isso, não havia motivos para mudar sua maneira viva e dramática de contar sua própria história. Os nomes de pessoas e lugares são conhecidos por mim, porém por boas razões os suprimi. $^{5}$ (CHILD, 2009[1861], p. 3-4. Tradução nossa).

Como se pode perceber na passagem acima, a própria revisora do texto confirma que o texto é uma autobiografia, ou seja, foi escrito pela própria Harriet Jacobs para contar a história de sua vida, os fatos e as situações de opressão vivenciadas em cativeiro e na fuga, assim como seu ponto de vista acerca da situação da mulher negra (e também da branca). Child reconhece a estranheza com que o público pode receber o texto como sendo de uma pessoa escravizada devido à qualidade da escrita e se apressa a apresentar os caminhos que levaram Harriet a escrever tão bem:

Surpreenderá, naturalmente, que uma mulher criada na escravidão possa escrever tão bem. Mas as circunstâncias vão explicar isso. Em primeiro lugar, a natureza a dotou de percepções rápidas. Em segundo lugar, a senhora, com quem vivieu até aos doze anos, foi uma amiga amável e atenciosa, que lhe ensinou a ler e soletrar. Em terceiro lugar, ela foi colocada em circunstâncias favoráveis, depois que chegou ao Norte, relacionando-se frequentemente com pessoas inteligentes, que sentiram um interesse amigável em seu bem-estar e estavam dispostas a dar-lhe oportunidades de autoaperfeiçoamento. ${ }^{6}$ (JACOBS (2009[1861], p. 3-4. Tradução nossa).

Foi desse ponto que Yellin partiu sua pesquisa e, por fim, conseguiu provar que a obra era do gênero autobiográfico e não uma Novel, como antes era conhecida.

\footnotetext{
${ }^{5}$ At her request, I have revised her manuscript; but such changes as I have made have been mainly for purposes of condensation and orderly arrangement. I have not added anything to the incidents, or changed the import of her very pertinent remarks. With trifling exceptions, both the ideas and the language are her own. I pruned excrescences a little, but otherwise I had no reason for changing her lively and dramatic way of telling her own story. The names of both persons and places are known to me; but for good reasons I suppress them.

${ }^{6}$ It will naturally excite surprise that a woman reared in Slavery should be able to write so well. But circumstances will explain this. In the first place, nature endowed her with quick perceptions. Secondly, the mistress, with whom she lived till she was twelve years old, was a kind, considerate friend, who taught her to read and spell. Thirdly, she was placed in favorable circumstances after she came to the North; having frequent intercourse with intelligent persons, who felt a friendly interest in her welfare, and were disposed to give her opportunities for selfimprovement
} 


\section{CONSIDERAÇÕES FINAIS}

Neste estudo, questionamo-nos sobre a importância de Incidents in the Life of a Slave Girl para o feminismo negro no Brasil e se a leitura dessa obra sobre o viés negro-feminista seria uma forma de compreendermos a importância da voz e da escrita da mulher negra escravizada sobre as situações de opressão vivenciadas em sua história para a lacuna existente nas narrativas de pessoas escravizadas no Brasil.

Após termos analisado a vida e a obra de Harriet Ann Jacobs, procuramos fazer uma interface dessa obra com o feminismo negro, já que os problemas pelos quais Harriet passou, como uma mulher escravizada, poderiam ser discutidos mais profundamente se lidos com um olhar feminista com o recorte de raça. Incidents é uma narrativa de sofrimento, que lida com questões importantes para o movimento negro e feminista, como: assédio sexual, maternidade na escravidão, questões de identidade, relações entre desiguais, objetificação da mulher (sobretudo da mulher negra).

Tantos nos EUA como nos Estados Unidos a mulher negra vivenciou no período da escravidão situações similares de opressão e de relações assimétricas de poder, nas quais a mulher negra não tinha sequer o direito a aprender a escrever, poder sobre seu corpo, e sua maternidade era desprovida de direitos, já que essa não podia educar seus filhos como queria e muitas vezes esses eram arrancados de seu poder logo ao nascer ou quando seus senhores o achassem necessário. Assim concluímos que a autobiografia Incidents in the Life of a Slave Girl pode ser considerada como relevante paraa memória da escravidão da mulher negra, uma obra feminista e pode ser indicada como uma obra importante para estudiosas/os, feministas negras (ou não) e leitoras/es da literatura brasileira, assim como pessoas que queiram conhecer mais sobre a história da escravidão negra nas Américas.

\section{REFERÊNCIAS}

BOLDEN, Tonya. Biographies. Digital Schomburg African American Women of the $19^{\text {th }} \quad$ Century. New York, 2000. Disponível em:http://digital.nypl.org/schomburg/writers_aa19/biographies.html/ Acesso: 30 jun. 2017.

CARNEIRO, Sueli. Enegrecer o feminismo: a situação da mulher negra na América Latina a partir de uma perspectiva de gênero. In: ASHOKA EMPREENDEDORES SOCIAIS: TAKANO CIDADANIA (Orgs.). Racismos contemporâneos. Rio de Janeiro; Takano Editora, 2003. 
CHILD, Lydia M. F. Introduction by the editor. In JACOBS, Harriet Ann. Incidents in the Life of a Slave Girl: written by herself. Boston: Harvard University Press, 2009 [1861].

COSTA, Sueli Gomes. Movimentos feministas, feminismos. Revista Estudos Feministas, Florianópolis, v. 12, p. 23 - 36, 2004.

DAVIS, Angela. Mulheres, Raça e Classe. Traduzido por Heci Regina Candiani. 1. ed. São Paulo: Boitempo, 2016.

DOUGLASS, Frederick. Narrativa da Vida de Frederick Douglass, Um Escravo Americano: Escrita Por Ele Mesmo. Traduzido por Leonardo Poglia Vidal. EUA: Createspace Independent Publishing Plataform, 2016.

FREYRE, Gilberto. Casa Grande \& Senzala: formação da família brasileira sob o regime de economia patriarcal. 50ª edição. São Paulo: Global, 2005.

GIACOMINI, Sonia M. Mulher e escrava: uma introdução histórica ao estudo da mulher negra no Brasil. Petrópolis: Vozes, 1988.

JACOBS, Harriet Ann. Incidents in the Life of a Slave Girl: written by herself. Boston: Harvard University Press, 2009 [1861].

JACOBS, Harriet Ann. Incidente na vida de uma escrava: contados por ela mesma. Traduzido por Waltensir Dutra. Rio de Janeiro: Editora Campus, 1988.

JESUS, Maria Carolina de. Quarto de despejo: diário de uma favelada. São Paulo: Livraria Francisco Alves, 1960.

LEJEUNE, Philippe. O pacto autobiográfico: de Rousseau à Internet. Traduzido por Jovita Maria Gerheim Noronha e Maria Inês Coimbra Guedes. Belo Horizonte: UFMG, 2008.

MENDES, Algemira de M. O discurso antiescravagista em Úrsula, de Maria Firmina dos Reis. Revista Cerrados, Brasília, v. 20, $\mathrm{n}^{\circ}$ 31, p. 75-92, 2011. Disponível em: <http://periodicos.unb.br/index.php/cerrados/article/viewFile/

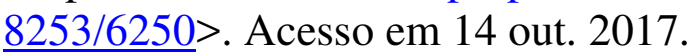

MOTT, Luiz. Rosa Egipcíaca. Uma santa africana no Brasil. Rio de Janeiro: Bertrand Brasil, 1993.

MOTT, Luiz. Rosa Egipcíaca: uma santa africana no Brasil colonial. Cadernos IHU Idéias, Ano 3, n. 38. São Leopoldo: UNISINOS, 2005.

NASCIMENTO, Abdias. O genocídio do negro brasileiro: processo de um racismo mascarado. São Paulo: Perspectivas, 2016. 
NORTHUP, Solomon. 12 Anos de Escravidão. Traduzido por Caroline Chang. Penguin Classics Companhia das Letras, 2014.

RAIMUNDO, Valdenice José; GEHLEN, Vitória; ALMEIDA, Daniely. Mulher negra inserção nos movimentos sociais feminista e negro. Cadernos de Estudos Sociais (FUNDAJ), Recife, v. 1, p. 1-8, 2006. Disponível em: $<$ http://www.fundaj.gov.br/images/stories/observanordeste/valdenice.pdf $>$.

Acesso: 20 nov. 2017.

REIS, Maria F. dos. Úrsula. 1859.Rio de Janeiro: Presença; INL, 1988.

REIS, Maria F. dos. Gupeva: romance brasiliense (1861). IN: MORAIS FILHO, José Nascimento. Maria Firmina: fragmentos de uma vida. São Luís: Imprensa do Governo do Maranhão, 1975a. p. 103-134.

REIS, Maria F. dos. Cantos à beira-mar (1871). IN: MORAIS FILHO, José Nascimento. Maria Firmina: fragmentos de uma vida. São Luís: Governo do Estado do Maranhão, 1975b.

REIS, Maria F. dos. A escrava (1887). IN: MORAIS FILHO, José Nascimento. Maria Firmina dos Reis: fragmentos de uma vida. São Luís: Governo do Estado do Maranhão, 1975c.

REIS, Maria F. dos. "Hino à liberdade dos escravos". IN: FARIA, Antônio A. M.; PINTO. Rosalvo G. (Orgs.) Poemas brasileiros sobre trabalhadores: uma antologia de domínio público. Belo Horizonte, FALE/UFMG, 2011. p. 53.

VERA CRUZ, Rosa M. E. Sagrada Teologia do Amor Divino das Almas Peregrinas. Brasil, 1763.

VIEIRA, Leonardo. Relatos de Escravos no Brasil em $1^{\mathrm{a}}$ Pessoa Revelam de Forma Pungente seu Sofrimento. O Globo, São Paulo, 21 de fevereiro de 2015. Disponível em: <https://oglobo.globo.com/sociedade/historia/relatos-de-cativosno-brasil-em-1-pessoa-revelam-de-forma-pungente-seu-sofrimento-15402413 >.

Acesso: 15 set. 2017.

YELIN, Jean Fagan. Introdução In: JACOBS, Harriet Ann. Incidentes na vida de uma escrava: contados por ela mesma. Traduzido por Waltensir Dutra. Rio de Janeiro: Editora Campus, 1988.

YELIN, Jean Fagan. Harriet Jacobs: a life. New York: Basic Civitas Books, 2004.

Recebido em 25/11/2017

Aceito em 19/12/2017 